\title{
Asthma and Height in Twins: A Cohort and Within-Pair Analyses Study
}

\author{
Jennifer L. P. Protudjer, ${ }^{1,2,3}$ Cecilia Lundholm, ${ }^{1}$ and Catarina Almqvist ${ }^{1,2,4}$ \\ ${ }^{1}$ Department of Medical Epidemiology and Biostatistics, Karolinska Institutet, Stockholm, Sweden \\ ${ }^{2}$ Centre for Allergy Research, Karolinska Institutet, Stockholm, Sweden \\ ${ }^{3}$ Institute of Environmental Medicine, Karolinska Institutet, Stockholm, Sweden \\ ${ }^{4}$ Astrid Lindgren Children's Hospital, Lung and Allergy Unit, Karolinska University Hospital, Stockholm, Sweden
}

\begin{abstract}
In singletons, asthma may be associated with shorter height and delayed growth during adolescence. Yet, these studies do not account for heritability of asthma, puberty/menarche, and height. We aimed to study the association between asthma and puberty in boys and menarche in girls, and height, in a cohort of twins and subsequently in same-sex twin pairs discordant for asthma. From a Swedish twin cohort, parentand self-reported data on asthma, puberty/menarche, and height were collected. Pubertal staging was established via the Petersen index. Logistic and linear regression was used to estimate associations between asthma and puberty/menarche and height, respectively. For within-pair analyses in twins discordant for asthma, conditional logistic and linear regression were used. Data on 2,658 (49.1\% boys) twins were included. Among boys, asthma prevalence was $8.2 \%$ at $8-9$ years and $10.2 \%$ at $13-14$ years. Corresponding numbers for girls were $4.2 \%$ and $4.9 \%$, respectively. In the entire cohort, no statistically significant associations were found between current asthma and puberty/menarche. Boys with asthma were shorter than boys without asthma at 8-9 years (on average, $1.86[0.17-3.56] \mathrm{cm}, p=.03$ ) and at 13-14 years (on average, $2.94[0.98-4.91] \mathrm{cm}, p=.003$ ) but not at 19-20 years. No such associations were found for girls. Within same-sex twin pairs discordant for asthma, no statistically significant associations were found for either sex. Twin boys, but not girls, with asthma were shorter than those without asthma. Non-statistically significant estimates from within-pair analyses suggest the association is partly confounded by genetic or familial environmental factors.
\end{abstract}

Keywords: adolescent, asthma, height, puberty, twins

Asthma is a prevalent disease among children that has been shown to switch from male to female predominance during adolescence by some (Almqvist et al., 2008; Asher et al., 2006; Nicolai et al., 2003), but not others (Protudjer et al., 2014). This suggests that events associated with puberty may play a role in the gender switch of asthma (Almqvist et al., 2008). An association between asthma and height has also been proposed, but is collectively inconclusive (Hauspie et al., 1977; Strunk et al., 2009; The Childhood Asthma Management Program Research Group, 2000). Asthma appears to be associated with shorter height (El-Sayed et al., 2010; Hauspie et al., 1976; 1979; Moudiou et al., 2003; Umlawska et al., 2013) and delayed growth (Hauspie et al., 1977) during adolescence, although the impact of childhood asthma on final adult height remains less understood (Kelly et al., 2012; Norjavaara et al., 2001). To date, this work has been done exclusively in singletons. For example, Polish children 5-18 years old with asthma of varying severities and duration of disease were shorter than healthy controls, and nearly $5 \%$ of those with asthma were very short in stature (Umlawska et al., 2013). In a retrospective study of Swedish women, childhood asthma was associated with significantly shorter adult height compared to women without a report of childhood asthma (Norjavaara et al., 2001). However, asthma (Fagnani et al., 2008; Lichtenstein \& Svartengren, 1997; Thomsen et al., 2008; 2010), pubertal staging (Koenis et al., 2013), menarche (van den Berg et al., 2006), and height (Hemani et al., 2013) are highly heritable. For example, a dizygous twin has three-fold greater risk of asthma compared to the general population if the co-twin

RECEIVED 15 November 2014; ACCEPTED 10 February 2015. First published online 12 March 2015.

ADDRESS FOR CORRESPONDENCE: Jennifer L. P. Protudjer, PhD, Department of Medical Epidemiology and Biostatistics, Karolinska Institutet, Box 281, Stockholm SE-171 77, Sweden. E-mail: jennifer.protudjer@ki.se 
has asthma, compared to the general population (Thomsen et al., 2010). Among monozygous twins, this risk increases to six-fold (Thomsen et al., 2010).

Twin studies provide an ideal way to gain greater understanding of diseases (Mayo, 2009), such as asthma, that are of genetic and environmental etiology. To this end, and in a cohort of Swedish twins followed prospectively from 8-9 years through 19-20 years, we sought to study the association between asthma and pubertal staging in boys and menarche in girls, and height. We first considered these associations in the entire cohort, and subsequently in samesex twin pairs discordant for asthma. This approach provided the opportunity to take heritability into account.

\section{Methods}

\section{Study Design and Subjects}

This analysis is based on the overarching Twin Study of Child and Adolescent Development (TCHAD), described elsewhere (Lichtenstein et al., 2007). Twin pairs were eligible if they were born in Sweden between May 1985 and December 1986 and their parents could communicate in Swedish. Starting at 8-9 years of age, twins have been prospectively followed at 13-14 years, 16-17 years, and 19-20 years. At 8-9 years, data were collected solely from the parents $(n=$ $1,339)$, while data were collected from the twins and their parents at $13-14$ years $(n=2,263$ and $n=1,063$, respectively), $16-17$ years ( $n=2,369$ and $n=1,067$, respectively), and from twins at $19-20$ years $(n=1,569)$. The population for this study was 2,658 (49.1\% boys) twins (1,329 twin pairs).

\section{Variables}

Zygosity for same-sex twin pairs was determined using an algorithm with a $95 \%$ probability of correctly classifying same-sex twin as either monozygotic or same-sex dizygotic (Lichtenstein et al., 2007).

Asthma status (presence vs. absence), based on validated questions from the International Study of Allergy and Asthma in Childhood (Asher et al., 1995) and described elsewhere (Mogensen et al., 2011), was ascertained based on parent-report at 8-9 years and 13-14 years, as well as retrospective parent-report from birth to 8-9 years at 8-9 year assessment. Current asthma prevalence was defined as asthma in the 12 months prior to 8-9 years and 13-14 years. Asthma persistence was also considered. Persistent early childhood asthma was defined as a retrospective parentreport of asthma prior to 8-9 years, and parent-report of asthma at 8-9 years. Persistent late childhood asthma from 8-9 years to 13-14 years was defined as asthma presence at both of these time points. Asthma discordance, based on parent-report of current asthma at 8-9 years, as well as at 13-14 years was considered in same-sex twins only.

Self-reported puberty data, including menarche in girls, were collected at 13-14 years. Boys were queried about skin changes, linear growth spurt, pubic hair growth, voice change, and beard growth. Possible responses for each characteristic above included: not yet started; just started; definitely started; complete/fully developed, with 1-4 points allocated respectively. In keeping with the recommendations from the Petersen index (Petersen et al., 1988) and described elsewhere (Protudjer et al., 2014), points associated with the latter three characteristics were summed for each boy. Each boy was then classified into mutually exclusive stages: pre-, early, mid-, late or post-puberty. Due to small sample sizes and a narrow age range at 13-14 years, which yielded little variation in pubertal staging, trichotomous categorization of pubertal staging, as previously used by our group (Protudjer et al., 2014), was not possible in the present study. Thus, a binary outcome of pubertal staging for boys was created from the above-described categories: early (pre- or early puberty) versus late (mid-, late-, or postpuberty). Rather than pubertal staging, girls were classified by self-reported menarche status at 13-14 years. As with boys, sample sizes and a narrow age range at 13-14 years mandated the creation of a binary outcome for pubertal staging. Upon further examination of the data, it became clear that the difference in pubertal staging was driven by menarche (no vs. yes). Further, 21 girls had responded to the menarche question but did not respond to all the questions required for ascertainment of pubertal staging. At 16-17 years, two girls (including one with asthma at 8-9 years) reported being unclear if they had reached menarche; these girls were excluded from further analyses. Parent-report of asthma status at 8-9 years was missing for 20 boys and 13 girls.

Data on height were collected via parent-report (8-9 years, 13-14 years) and twin-report (16-17 years, 19-20 years). Measured and reported heights have been shown elsewhere to be well correlated in similar-aged study populations (Brettschneider et al., 2012; Legleye et al., 2014; Yoshitake et al., 2012). Height data from all waves were reviewed for implausible values. This led to the exclusion of height data at 8-9 years for two twins who had parentreported heights of $<50 \mathrm{~cm}$ (range $26-34 \mathrm{~cm}$ ), and at 1617 years for 22 twins, who self-reported heights $<100 \mathrm{~cm}$ (range $0.5-84 \mathrm{~cm}$ ).

\section{Confounding Variables}

Using directed acyclic graphs (Moodie \& Stephens, 2010), which permit visual description of epidemiological relationships, we identified potential confounders. Based on their associations to asthma, and pubertal staging, menarche or height, age (Nicolai et al., 2003) and birth weight (Örtqvist et al., 2009; Wang et al., 2012) were included as confounders in our regression models for the entire cohort. Age was calculated as the difference between date of questionnaire completion and date of birth. Birth weight for all twins was obtained from the Swedish Medical Birth Register, held by the National Board of Health and Welfare. 


\section{Statistical Analyses}

Descriptive statistics included $n$, percentage, and mean \pm standard deviation, and tests for normal distribution of height. For the entire cohort, logistic regression was used to analyze associations between exposure variables (current asthma, persistent early- or late-childhood asthma) and dichotomous outcomes. Also, for the entire cohort, linear regression was used for the continuous outcome of height. Standard errors were in both cases estimated using the sandwich estimator for clustered observations, to account for within-pair correlations. For within-pair analyses, that is, analyses with adjustment for everything twins share within pairs, conditional linear regression was used. For within-pair analyses, only birth weight was considered as a confounder, as each twin pair had the same age. Undeterminable zygosity was classified as unknown $(n=17)$; these participants were subsequently excluded from withinpair analyses.

If the effect of the exposure variable does not differ between the within-pair analyses and those of the entire cohort, then genetic and shared environmental factors contribute little to the association. As the within-pair analysis was not stratified on zygosity, this analysis cannot completely (100\%) account for the heritability of asthma, puberty, and height.

For logistic regression analyses, odds ratios (OR) with corresponding 95\% confidence intervals (95\% CI) are presented. For linear regression and conditional linear regression analyses, means and standard errors, estimated from the regression models at the mean of the covariates, are presented graphically, with estimated coefficients, 95\%CI and $p$-values presented in text. All analyses were stratified by sex. Statistical significance was set at $p<.05$. Analyses were performed with STATA 11.0 (StatCorp LP, College Station, TX, USA).

Ethical permission was received from Regional Ethical Review Board of the Karolinska Institutet, Stockholm, Sweden.

\section{Results}

Characteristics of the 2,658 (1,306 [49.1\%] boys) twins included in this study are presented in Table 1. Participants responded to questionnaires at mean ages of $8.7 \pm 0.5$ years, $13.7 \pm 0.5$ years, $16.7 \pm 0.5$ years, and $19.7 \pm 0.5$ years. At 8-9 years and 13-14 years, asthma prevalence amongst boys was $8.2 \%$ and $10.2 \%$, respectively. The corresponding numbers for girls were $4.2 \%$ and $4.9 \%$. At $19-20$ years, $11.1 \%$ of boys and $10.6 \%$ of girls had self-reports of asthma. At age 13-14, an approximately equal number of boys were in early versus late puberty and most girls (705/1,046 [66.6\%]) had reached menarche.

In the entire cohort, no statistically significant associations were found between current asthma at either 8-9 years, or 13-14 years, or persistent early- or late-childhood asthma, and self-reported pubertal staging at 13-14 years for boys or menarche in girls (Table 2).

Figure 1 is a presentation of the adjusted estimates of mean height from linear regression for the entire cohort by asthma presence versus absence. Cross-sectionally, boys with asthma were shorter than boys without asthma at 89 years (on average, $1.86[0.17-3.56] \mathrm{cm}, p=.03$ ) and at $13-14$ years (on average, $2.94[0.98-4.91] \mathrm{cm}, p=.003$ ) but did not reach statistical significance at 19-20 years (on average, $1.74(-0.08-3.56) \mathrm{cm}, p=.06)$. The corresponding cross-sectional findings for girls did not reach statistical significance at any of these time points (e.g., 8-9 years $(0.95$ $(-0.55-2.46) \mathrm{cm}, p=.215)$. In longitudinal analyses, asthma at 8-9 years was not statistically significantly associated with height differences through 19-20 years. Asthma at 13-14 years was associated with shorter height in boys at 16-17 years (on average $2.12(0.62-3.62) \mathrm{cm}, p=.006)$, but not with height at 19-20 years. Corresponding numbers for girls did not reach statistical significance (for example: the result for girls with asthma at 13-14 years and height at 16-17 years was $1.15(-0.82-3.11) \mathrm{cm}, p=.254)$.

Table 3 is a summary of the descriptive characteristics for same-sex twin pairs by asthma discordance. Among samesex twins, there were 38 and 36 twin pairs of boys who were discordant for asthma at 8-9 years and 13-14 years, respectively. The corresponding numbers for girls were 24 and 20. The numbers for within-pair analyses on pubertal stage were too small for analyses as there were no more 4-6 female pairs and 13-15 male pairs who were discordant for both asthma and puberty stage (Table 3 ).

Figure 2 is a presentation of the estimated mean heights for same-sex asthma discordant twin pairs, when adjusted for everything the twins have in common within the pair (conditional analyses). In both cross-sectional and longitudinal analyses within pairs, associations between asthma and height were attenuated and not statistically significant for either sex.

\section{Discussion}

In a cohort of twins, we identified some statistically significant cross-sectional and longitudinal associations between asthma and shorter height among boys but not girls. These differences were attenuated and no longer statistically significant in within-pair analyses in twin pairs discordant for asthma status. Our observations of shorter height among those with asthma compared to those without asthma are consistent with some (El-Sayed et al., 2010; Hauspie et al., 1976; 1979; Moudiou et al., 2003; Umlawska et al., 2013), but not all (Kaplan et al., 1987; Moudiou et al., 2003) reports from singletons. But, the use of twin data permits greater insight into the potential causality of associations between asthma and height than was possible in reports from singletons. The estimates from within-pair analyses were attenuated compared to those of the entire cohort, 
TABLE 1

Study Population of a Cohort of Twins

\begin{tabular}{|c|c|c|c|c|c|c|c|c|c|}
\hline \multirow[b]{3}{*}{ Participant characteristics } & & \multicolumn{4}{|c|}{ All participants } & \multicolumn{4}{|c|}{$\begin{array}{l}\text { Participants with parent-reported asthma } \\
\text { at 8-9 years }\end{array}$} \\
\hline & & \multicolumn{2}{|r|}{ Boys } & \multicolumn{2}{|r|}{ Girls } & \multicolumn{2}{|r|}{ Boys } & \multicolumn{2}{|r|}{ Girls } \\
\hline & & $n$ & $\%$ & $n$ & $\%$ & $n$ & $\%$ & $n$ & $\%$ \\
\hline \multirow{6}{*}{$\begin{array}{l}\text { Sex } \\
\text { Zygosity }\end{array}$} & & 1,306 & 49.1 & 1,352 & 50.9 & 105 & 65.2 & 56 & 34.8 \\
\hline & $M Z^{*}$ & 486 & 37.2 & 484 & 35.8 & 44 & 41.9 & 27 & 48.2 \\
\hline & SS-DZ† & 340 & 26.0 & 348 & 25.7 & 24 & 22.9 & 9 & 16.1 \\
\hline & OS-DZ $\ddagger$ & 386 & 29.6 & 386 & 28.6 & 31 & 29.5 & 17 & 30.4 \\
\hline & Unknown§ & 18 & 1.4 & 30 & 2.2 & 0 & 0.0 & 1 & 1.8 \\
\hline & Missing & 76 & 5.8 & 104 & 7.7 & 6 & 5.7 & 2 & 3.6 \\
\hline \multicolumn{10}{|c|}{ Pubertal development at $13-14$ years ${ }^{* *}$} \\
\hline & Early & 526 & 51.8 & - & - & 42 & 51.2 & - & - \\
\hline & Late & 490 & 48.2 & - & - & 40 & 48.8 & - & - \\
\hline \multicolumn{10}{|l|}{ Menarche at $13-14$ years } \\
\hline & No menarche & - & - & 354 & 33.4 & - & - & 11 & 27.5 \\
\hline & Menarche & - & - & 705 & 66.6 & - & - & 29 & 72.5 \\
\hline & & $n$ & mean \pm SD & $\mathrm{n}$ & mean \pm SD & $n$ & mean \pm SD & $n$ & mean $\pm \mathrm{SD}$ \\
\hline Birth weight (g) & & 1,278 & $2,635.3 \pm 529.6$ & 1,331 & $2,556.9 \pm 516.3$ & 105 & $2,483.1 \pm 528.3$ & 56 & $2,536.8 \pm 510.9$ \\
\hline \multicolumn{10}{|l|}{ Age $(y)$} \\
\hline & $8-9$ years & 1,306 & $8.7 \pm 0.5$ & 1,352 & $8.7 \pm 0.5$ & 105 & $8.7 \pm 0.5$ & 56 & $8.8 \pm 0.5$ \\
\hline & $13-14$ years & 1,306 & $13.7 \pm 0.5$ & 1,352 & $13.7 \pm 0.5$ & 105 & $13.7 \pm 0.5$ & 56 & $13.8 \pm 0.5$ \\
\hline & $16-17$ years & 1,306 & $16.7 \pm 0.5$ & 1,352 & $16.7 \pm 0.5$ & 105 & $16.7 \pm 0.5$ & 56 & $16.8 \pm 0.5$ \\
\hline & 19-20 years & 1,306 & $19.7 \pm 0.5$ & 1,352 & $19.7 \pm 0.5$ & 105 & $19.7 \pm 0.5$ & 56 & $19.8 \pm 0.5$ \\
\hline \multicolumn{10}{|l|}{ Height (cm) } \\
\hline & $8-9$ years & 972 & $133.7 \pm 6.5$ & 1,010 & $132.5 \pm 6.6$ & 71 & $131.6 \pm 7.2$ & 41 & $131.7 \pm 4.6$ \\
\hline & $13-14$ years & 911 & $163.6 \pm 9.2$ & 1,008 & $161.4 \pm 6.9$ & 72 & $162.3 \pm 9.5$ & 38 & $160.8 \pm 5.6$ \\
\hline & $16-17$ years & 1,029 & $176.3 \pm 8.2$ & 1,140 & $165.3 \pm 6.5$ & 79 & $175.1 \pm 6.2$ & 46 & $164.2 \pm 5.6$ \\
\hline & $19-20$ years & 623 & $180.4 \pm 6.7$ & 946 & $166.4 \pm 6.1$ & 46 & $178.7 \pm 6.5$ & 39 & $166.0 \pm 5.6$ \\
\hline Asthma & & $\mathrm{n}$ & $\%$ & $\mathrm{n}$ & $\%$ & $\mathrm{n}$ & $\%$ & $\mathrm{n}$ & $\%$ \\
\hline \multicolumn{10}{|l|}{$8-9$ years $(n=2,027)$} \\
\hline & No & 1,175 & 91.8 & 1,280 & 95.8 & - & - & - & - \\
\hline & Yes & 105 & 8.2 & 56 & 4.2 & - & - & - & - \\
\hline \multicolumn{10}{|l|}{$13-14$ years $(n=1,879)$} \\
\hline & No & 875 & 89.8 & 979 & 95.1 & 12 & 17.1 & 9 & 23.7 \\
\hline & Yes & 99 & 10.2 & 50 & 4.9 & 58 & 82.9 & 29 & 76.3 \\
\hline \multicolumn{10}{|l|}{$19-20$ years $(n=1,305)$} \\
\hline & No & 552 & 88.9 & 828 & 89.4 & 11 & 22.5 & 10 & 26.3 \\
\hline & Yes & 69 & 11.1 & 98 & 10.6 & 38 & 77.5 & 28 & 73.7 \\
\hline Asthma timing & & $\mathrm{n}$ & $\%$ & $\mathrm{n}$ & $\%$ & & & & \\
\hline No asthma & & 1,174 & 91.9 & 1,279 & 96.0 & - & - & - & - \\
\hline $\begin{array}{l}\text { Persistent early childhood } \\
\text { asthma†† }\end{array}$ & & 103 & 8.1 & 53 & 4.0 & - & - & - & - \\
\hline Asthma from 8-9 to 13-14 & years & $\mathrm{n}$ & $\%$ & $\mathrm{n}$ & $\%$ & & & & \\
\hline No asthma & & 847 & 93.6 & 960 & 97.1 & - & - & - & - \\
\hline $\begin{array}{l}\text { Persistent late childhood } \\
\text { asthmałf }\end{array}$ & & 58 & 6.4 & 29 & 2.9 & - & - & - & - \\
\hline
\end{tabular}

Note: *Monozygotic twins; †Same sex dizygotic twins; $\ddagger$ Opposite sex dizygotic twins; §Unknown zygosity; ${ }^{* *}$ Pre/early versus mid/late/post as per Peterson et al. (1988); ††Retrospective parental report of asthma prior to 8-9 years and parental report of asthma at 8-9 years; $\ddagger \ddagger$ Parental report of asthma at $8-9$ years. and 13-14 years.

suggesting partial confounding by genes or shared familial environment. In other words, our findings provide modest evidence that differences in height among boys by asthma status may be partly attributable to genes or shared familial environment, rather than asthma. This is interesting, as there has been a concern about the impact of asthma on height for many years (El-Sayed et al., 2010; Hauspie et al., 1976; 1977; 1979; Moudiou et al., 2003; The Childhood Asthma Management Program Research Group, 2000; Umlawska et al., 2013). However, caution is warranted when interpreting the collective results in relation to familial confounding as the confidence intervals from the within-pair analyses are wide enough to cover the estimates from the cohort analysis.
Our null findings between asthma and self-reported pubertal staging in the entire cohort are consistent with some (Neville et al., 1996; Skrzypuklec et al., 2007), but not all studies (Drosdzol et al., 2007; Hauspie et al., 1977; Moudiou et al., 2003). An inconclusive pattern in the collective results may be attributable to different methods, such as categorization by age (Moudiou et al., 2003; Neville et al., 1996) or validated scales (Drosdzol et al., 2007; Hauspie et al., 1977), of establishing pubertal staging. In contrast to newer ways of determining pubertal staging (Gasser et al., 2013), the validated Peterson index, which we applied to our data on boys, does not include information on height to establish pubertal staging (Petersen et al., 1988). 
TABLE 2

Unadjusted and Adjusted Odds Ratios for Asthma in Association with Pubertal Staging/Menarche in a Cohort of Twins

\begin{tabular}{|c|c|c|c|c|c|c|}
\hline & \multicolumn{3}{|c|}{ Boys* } & \multicolumn{3}{|c|}{ Girls* } \\
\hline & \multirow[b]{2}{*}{$n$} & \multicolumn{2}{|c|}{ Late puberty } & \multirow[b]{2}{*}{$n$} & \multicolumn{2}{|c|}{ Menarche } \\
\hline & & OR & $95 \% \mathrm{Cl}$ & & OR & $95 \% \mathrm{Cl}$ \\
\hline \multicolumn{7}{|c|}{ Asthma at 8-9 years } \\
\hline Unadjusted & 996 & 1.02 & $0.62 ; 1.67$ & 1,051 & 1.38 & $0.68 ; 2.79$ \\
\hline Adjusted $\dagger$ & 977 & 1.10 & $0.65 ; 1.84$ & 1,037 & 1.37 & $0.65 ; 2.89$ \\
\hline \multicolumn{7}{|c|}{ Asthma at $13-14$ years } \\
\hline Unadjusted & 923 & 0.77 & $0.48 ; 1.23$ & 974 & 1.53 & $0.81 ; 2.89$ \\
\hline Adjusted $\dagger$ & 905 & 0.82 & $0.52 ; 1.32$ & 960 & 1.43 & $0.73 ; 2.80$ \\
\hline \multicolumn{7}{|c|}{ Persistent childhood asthma $\ddagger$} \\
\hline Unadjusted & 993 & 1.08 & $0.65 ; 1.77$ & 1,049 & 1.29 & $0.63 ; 2.62$ \\
\hline Adjusted $\dagger$ & 974 & 1.18 & $0.71 ; 1.98$ & 1,035 & 1.29 & $0.60 ; 2.76$ \\
\hline \multicolumn{7}{|c|}{ Persistent asthma from 8-9 to $13-14$ years } \\
\hline Unadjusted & 872 & 0.98 & $0.74 ; 1.30$ & 953 & 1.21 & $0.81 ; 1.80$ \\
\hline Adjusted $\dagger$ & 872 & 1.00 & $0.74 ; 1.33$ & 940 & 1.17 & $0.77 ; 1.79$ \\
\hline
\end{tabular}

Note: *Reference groups are early puberty (boys) and no menarche (girls); †Adjusted for age at respective visit(s) and birth weight; $¥$ Based on retrospective and current parent-report of asthma at 8-9 years.

TABLE 3

Zygosity, Puberty, and Height in Asthma Discordant Same-Sex Twin Pairs

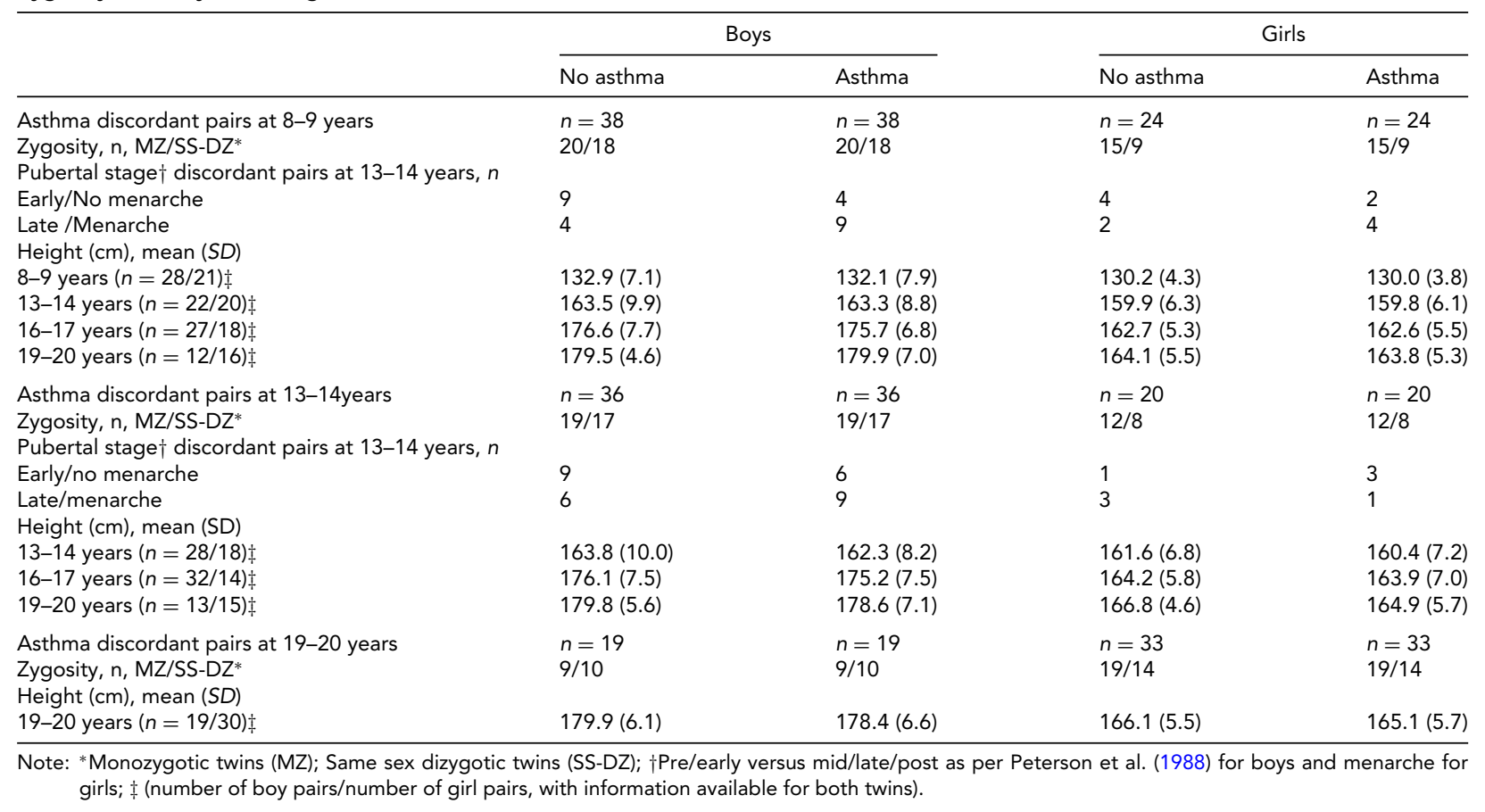

The adolescent growth spurt is a marker of sexual maturation (WHO Expert Committee on Physical Status, 1995). Boys reach their pubertal debut at approximately 11.5 years, approximately a year later than girls. Boys' progression through puberty lasts for $\sim 3.5$ years, and is shorter than that for girls ( $\sim 4.2$ years). For both boys and girls, the growth spurt begins in puberty and is completed by late puberty. On average, girls reach their growth spurt by $\sim 12$ years and boys reach their growth spurt 2 years later (WHO Expert Committee on Physical Status, 1995). In our study, self-reported pubertal staging was during the 13-14 year assessment, the age at which boys begin to reach their growth spurt, but 1-2 years after girls would have reached their growth spurt on average. In cross-sectional analyses of asthma and height in the entire cohort, boys with asthma were significantly shorter than boys without asthma at 8-9 years and at 13-14 years, but did not differ significantly by 19-20 years. Similar to some previous reports on 13- to 14-year-old boys (Hauspie et al., 1976; 1977; 1979), and in keeping with those of girls (Drosdzol et al., 2007), 13-to 14-year-old boys, but not girls with asthma in the entire cohort were statistically significantly shorter than their same-sex peers without asthma. No statistically significant differences between asthma and height were found for girls in either cross-sectional or 
A. Boys, cross-sectional associations between height and asthma*

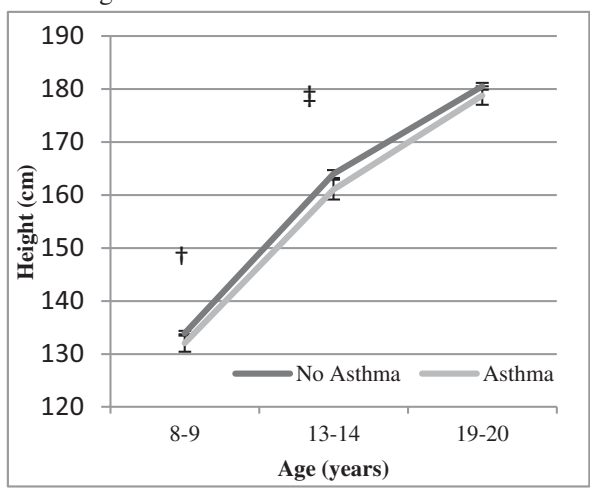

C. Boys with asthma at 8-9, and longitudinal height outcomes

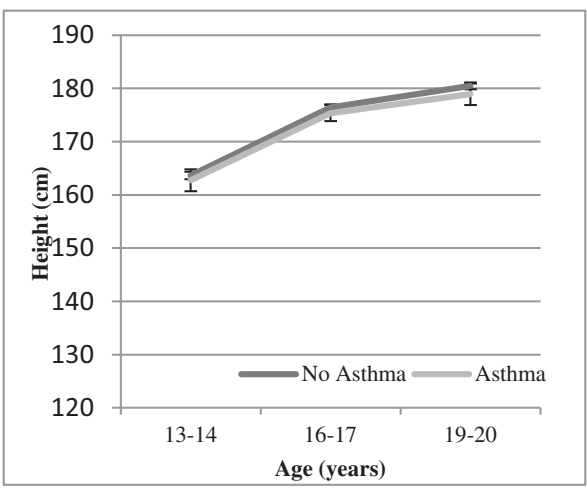

E. Boys with asthma at 13-14 years, and longitudinal height outcomes

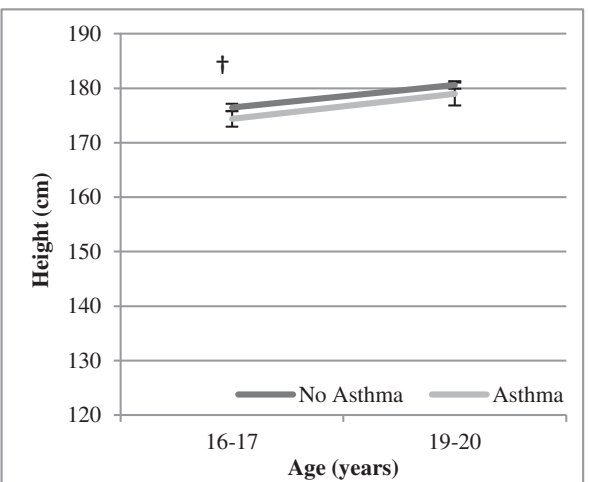

B. Girls, cross-sectional outcomes between height and asthma*

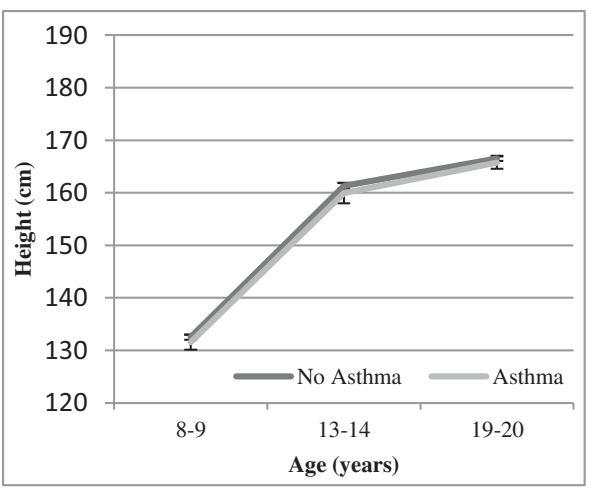

D. Girls with asthma at $8-9$, and longitudinal height outcomes

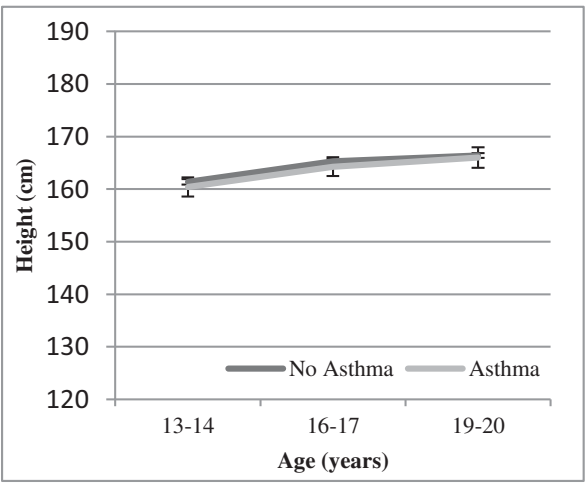

F. Girls with asthma at 13-14 years, and longitudinal height outcomes

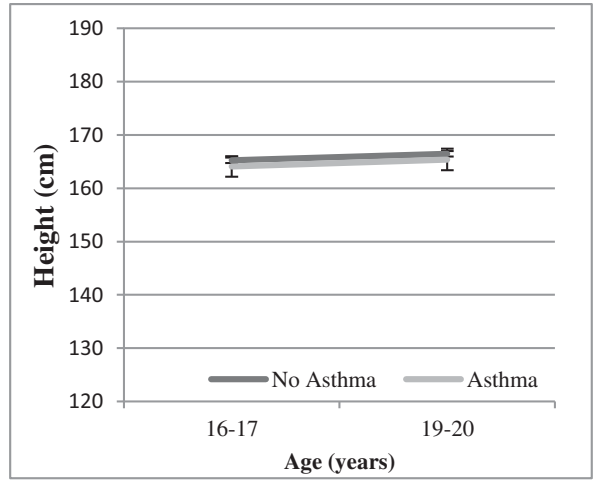

\section{FIGURE 1}

Mean height with $95 \%$ confidence intervals, estimated from linear regression models with asthma as a predictor of height (cm) from 8-9 years through 19-20 years, adjusted for birth weight and age in a cohort of Swedish twins

Note: *Asthma not assessed at $16-17$ years; $\dagger p<.05 ; \ddagger p<.005$.

longitudinal analyses in the entire cohort or within-pair analyses. One may speculate that the null findings at 8-9 years and 13-14 years may, in part, be attributable to a low prevalence of asthma among girls at these ages, thereby potentially limiting our ability to identify statistically significant observations. By 19-20 years, more than twice as many girls reported asthma than at the previous time points. As such, we would have anticipated that differences in height by asthma status at 19-20 years would have been identified if such differences existed. From adolescence onward, girls typically (Almqvist et al., 2008; Nicolai et al., 2003) but not always (Protudjer et al., 2014) have a higher prevalence of asthma than in childhood. Girls with asthma in adolescence often have a more severe disease phenotype than boys, as 
A. Boys, cross-sectional associations between asthma status and height*

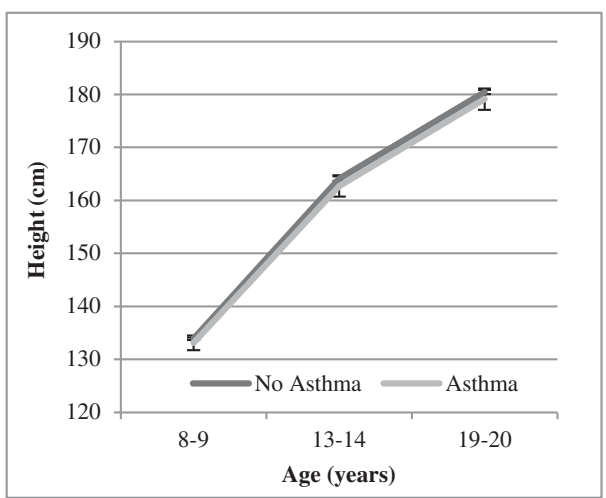

C. Boys by asthma status at $8-9$ years, and longitudinal height outcomes

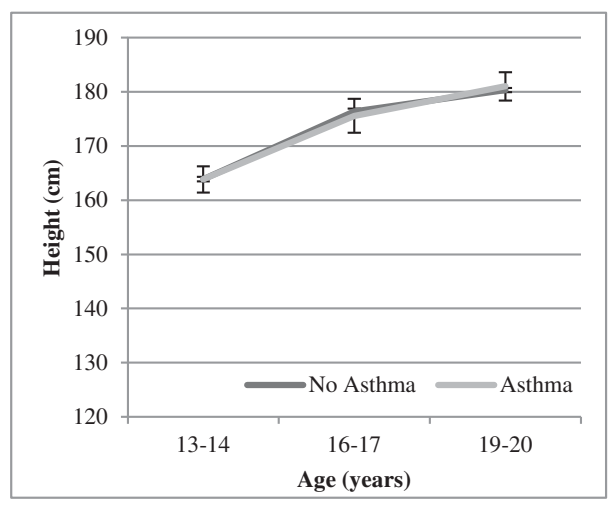

E. Boys by asthma status at 13-14 years, and longitudinal height outcomes

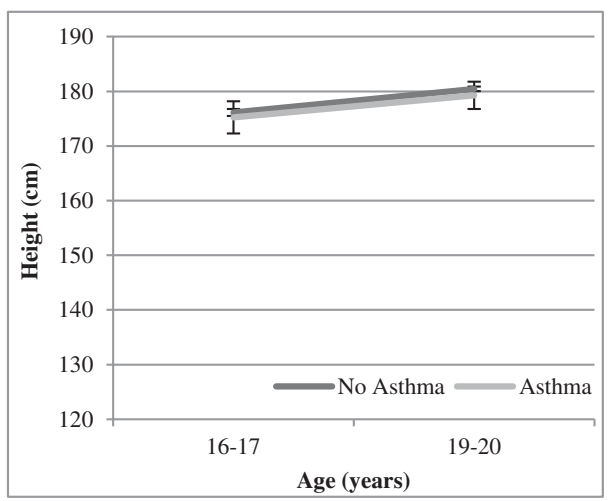

B. Girls, cross-sectional associations

between asthma status and height*

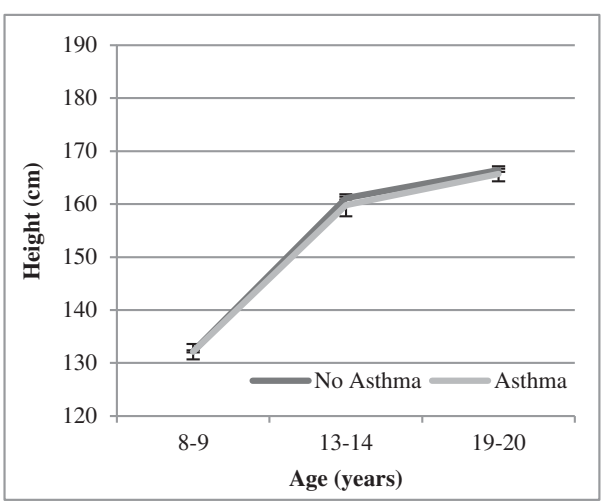

D. Girls by asthma status at $8-9$ years, and longitudinal height outcomes

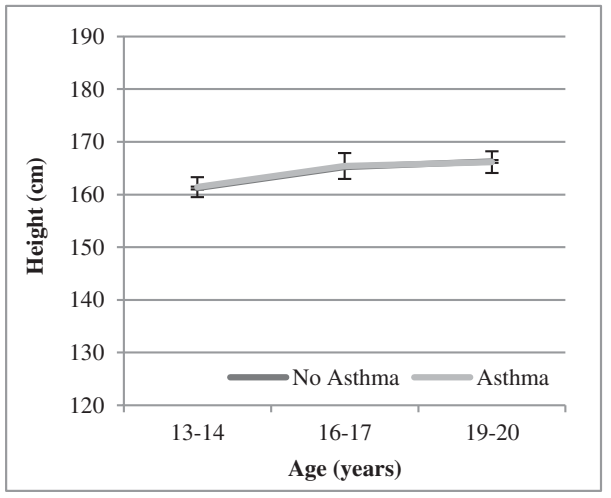

F. Girls by asthma status at 13-14 years, and longitudinal height outcomes

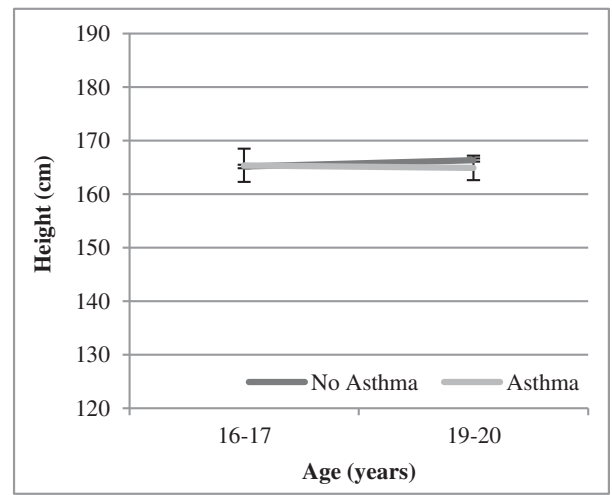

\section{FIGURE 2}

Mean height with $95 \%$ confidence intervals, estimated from conditional linear regression models with asthma as a predictor of height (cm) from 8-9 years through 19-20 years, adjusted for birth weight, using twin pairs that are discordant for asthma in a sample of same-sex twins.

evidenced by higher emergency room visits and hospitalization rates (Akinbami et al., 2011). Although our data precluded consideration to disease severity, disease severity is associated with a greater odds of asthma persistence (Tai et al., 2014) and oral steroid use (Schofield, 2014), both of which have been associated with delayed attainment of adult height (Martin et al., 1981).

Within-pair analyses of asthma and height yielded a pattern of results that was attenuated compared to that of the entire cohort. Taken collectively, the differences in the 
results of analyses of the entire cohort and within-pair analyses suggests that the association between asthma and height is confounded by genetic and/or shared environmental factors.

We acknowledge the weaknesses of our study. First, height was ascertained by parent-reports at 8-9 years and 13-14 years, and by twin-report at 16-17 years and 1920 years. Although measured height is the gold standard, this was impractical in a large cohort such as TCHAD. Importantly, others have shown a strong correlation between reported and measured heights (Brettschneider et al., 2012; Legleye et al., 2014; Yoshitake et al., 2012) in studies of children of similar ages to the twins in the present study. Second, small sample sizes precluded consideration of asthma medication or stratification by zygosity. Nonetheless, our approach permitted adjustment for at least 50\% of segregating genes, which all dizygotic twins, and indeed all siblings share. Moreover, twins share a common environment from conception and through childhood. Third, although pubertal development exists along a continuum, we were only able to establish a dichotomous variable for pubertal staging, thereby limiting the sensitivity of our pubertal staging classification.

To our knowledge, this is one of the first reports on asthma and height using a twin design. Our findings in the entire cohort correspond well with the associations of asthma and height in singletons (El-Sayed et al., 2010; Hauspie et al., 1976; 1979; Moudiou et al., 2003; Umlawska et al., 2013). Thus, our results both are generalizable to singletons and extend the understanding of asthma and height.

\section{Conclusion}

In a cohort of Swedish twins, we identified that twin boys, but not girls with asthma were of shorter height than those without asthma. Estimates from within-pair analyses were attenuated and non-significant, suggesting the association is partly confounded by genetic or familial environmental factors.

\section{Acknowledgments}

We acknowledge financial support from the Swedish Research Council (Grant no. 2011-3060) and through the Swedish Initiative for Research on Microdata in the Social And Medical Sciences (SIMSAM) framework Grant no. 340-2013-5867, the Strategic Research Program in Epidemiology at Karolinska Institutet, the Swedish Heart Lung Foundation (Contract no. 20120480), the Swedish Asthma and Allergy Association (Grants no. 2010048-K, 2011051-K, 2012056-K, and 2013049-K) and the regional agreement on medical training and clinical research between Stockholm County Council and Karolinska Institutet (ALF; Contract no. 20130422 and 20140322). The Swedish Twin Registry was financially supported by the Swedish Ministry of Education and Research. Jennifer Protudjer was first supported by European Respiratory Society Long Term Research Fellowship no. 117-2011, then a Canadian Institutes of Health Research Post-Doctoral Fellowship during this project.

\section{References}

Akinbami, L. J., Moorman, J. E., \& Liu, X. (2011). Asthma prevalence, health care use, and mortality: United States, 2005-2009. National Health Statistics Reports, 12, 1-14.

Almqvist, C. A., Worm, M., \& Leynaert, B. (2008). Impact of gender on asthma in childhood and adolescence: A GA2LEN review. Allergy, 63, 47-57.

Asher, M. I., Keil, U., Anderson, H. R., Beasley, R., Crane, J., Martinez, F., ... Williams, H. C. (1995). International study of asthma and allergies in childhood (ISAAC): Rationale and methods. European Respiratory Journal, 8, 483491.

Asher, M. I., Montefort, S., Björkstén, B., Lai, C. K., Strachan, D. P., Weiland, S. K., ... ISAAC Phase Three Study Group. (2006). Worldwide time trends in the prevalence of asthma symptoms of asthma, allergic rhinoconjunctivitis, and eczema in childhood: ISAAC Phases one and three repeat multicountry cross-sectional surveys. Lancet, 368, 733-743.

Brettschneider, A.-K., Ellert, U., \& Schaffrath Rosario, A. (2012). Comparison of BMI derived from parent-reported height and weight with measured values: Results from the German KiGGS study. International Journal of Environmental Research and Public Health, 9, 632-647.

Drosdzol, A., Wilk, K., \& Nowosielski, K. (2007). The influence of bronchial asthma on sexual maturation of girls. Journal of Physiology and Pharmacology, 1, 155-163.

El-Sayed, Z. A., Hamza, R. T., Sayed, N.-D., \& Mahmoud, N. H. (2010). Effect of inhaled corticosteroids on growth and puberty in Egyptian asthmatic children and adolescents. Pakistan Journal of Biological Sciences, 13, 977-984.

Fagnani, C., Annesi-Maesano, I., Brescianini, S., D’Ippolito, C., Medda, E., Nistico, L., ... Stazi, M. A. (2008). Heritability and shared genetic effects of asthma and hay fever: An Italian study of young twins. Twin Reseach and Human Genetics, 11, 121-131.

Gasser, T., Molinari, L., \& Largo, R. (2013). A comparison of pubertal maturity and growth. Annals of Human Biology, 40, 341-347.

Hauspie, R. C., Gyenis, G., Alexander, F., Simon, G., Susanne, C., \& Madách, A. (1979). Heights and weights of Hungarian and Belgian asthmatic boys. Human Biology, 51, 507-521.

Hauspie, R., Susanne, C., \& Alexander, F. (1976). A mixed longitudinal study of the growth in height and weight in asthmatic children. Human Biology, 48, 271-283.

Hauspie, R., Susanne, C., \& Alexander, F. (1977). Maturational delay and temporal growth retardation in asthmatic boys. Journal of Allergy and Clinical Immunology, 59, 200-206.

Hemani, G., Yang, J., Vinkhuyzen, A., Powell, J. E., Willemsen, G., Hottenga, J. J., ... Visscher, P. M. (2013). Inference of the genetic architecture underlying BMI and height with the use of 20,240 sibling pairs. American Journal of Human Genetics, 93, 865-875. 
Kaplan, B. A., Brush, G., \& Mascie-Taylor, C. G. (1987). The relationship of childhood asthma and wheezy bronchitis with height, weight and body mass index. Human Biology, 59, 921-931.

Kelly, H. W., Sternberg, A. L., Lescher, R., Fuhlbrigge, A. L., Williams, P., Zeiger, R. S., ... CAMP Research Group. (2012). Effect of inhaled corticosteroids in childhood on adult height. New England Journal of Medicine, 367, 904912.

Koenis, M. M., Brouwer, R. M., van Baal, G. C., van Soelen, I. L., Peper, J. S., van Leeuwen, M, ... Hulshoff Pol, H. E. (2013). Longitudinal study of hormonal and physical development in young twins. Journal of Clinical Endocrinology and Metabolism, 98, E518-527.

Legleye, S., Beck, F., Spilka, S., \& Chau, N. (2014). Correction of body-mass index using body-shape perception and socioeconomic status in adolescent self-report surveys. PLoS One, 9, e976768.

Lichtenstein, P., \& Svartengren, M. (1997). Genes, environment, and sex: Factors of importance in atopic diseases in 7-9-year-old Swedish twins. Allergy, 52, 1079-1086.

Lichtenstein, P., Tuvblad, C., Larsson, H., \& Carlström, E. (2007). The Swedish twin study of CHild and adolescent development: The TCHAD-Study. Twin Research and $\mathrm{Hu}$ man Genetics, 10, 67-73.

Martin, A. J., Landau, L. I., \& Phelan, P. D. (1981). The effect of growth on childhood asthma. Acta Paediatrica Scand, 70, 683-688.

Mayo, O. (2009). Early research on human genetics using the twin method: Who really invented the method? Twin Research and Human Genetics, 12, 237-245.

Mogensen, N., Larsson, H., Lundholm, C., \& Almqvist, C. (2011). Association between childhood asthma and ADHA symptoms in adolescence - A prospective populationbased twin study. Allergy, 66, 1224-1230.

Moodie, E. M. M., \& Stephens, D. A. (2010). Use of directed acyclic graphs to detect limitations of traditional regression in longitudinal studies. International Journal of Public Health, 55, 701-703.

Moudiou, T., Theophilatou, D., Prifits, K., \& Papadimitriou, A. (2003). Growth of asthmatic children before long-term treatment with inhaled corticosteroids. Journal of Asthma, 40, 667-671.

Neville, R. G., McCowan, C., Thomas, G., \& Crombie, I. K. (1996). Asthma and growth -- cause for concern? Asthma and growth in Tayside children. Annals of Human Biology, 23, 323-331.

Nicolai, T., Pereszlenyiova-Bliznakova, L., Illi, S., Reinhardt, D., \& von Mutius, E. (2003). Longitudinal follow-up of the changing gender ratio in asthma from childhood to adulthood: Role of delayed manifestation in girls. Pediatric Allergy and Immunology, 14, 280-283.

Norjavaara, E., Gerhardsson de Verdier, M., \& Lindmark, B. (2001). Adult height in women with childhood asthma - A population-based study. Pharmacoepidemiology and Drug Safety, 10, 121-125.

Örtqvist, A. K., Lundholm, C., Carlström, E., Lichtenstein, P., Cnattingius, S., \& Almqvist, C. (2009). Familial factors do not confound the association between birth weight and childhood asthma. Pediatrics, 124, e737-743.

Petersen, A. C., Crockett, L., Richards, M., \& Boxer, A. (1988). A self-report measure of pubertal status: Reliability, validity, and initial norms. Journal of Youth and Adolescence, 17, 117133.

Protudjer, J. L. P., Lundholm, C., Bergstrom, A., Kull, I., \& Almqvist, C. (2014). Puberty and asthma in a cohort of Swedish children. Annals of Allergy, Asthma \& Immunology, 112, 78-79.

Schofield, M. L. (2014). Asthma pharmacotherapy. Otolaryngolic Clinics of North America, 47, 55-64.

Skrzypuklec, V., Doniec, Z., Drosdzol, A., Nowosielski, K., \& Pawlinska-Chmara, R. (2007). The influence of bronchial asthma on premenstrual syndrome prevalence amongst girls. Journal of Physiology and Pharmacology, 58, 639-646.

Strunk, R. C., Sternberg, A. L., Szefler, S. J., Zeiger, R. S., Bender, B., Tonascia, J., . . CAMP Research Group. (2009). Long-term budesonide or nedocromil treatment, once discontinued, does not alter the course of mild to moderate asthma in children. Journal of Pediatrics, 154, 682-687.

Tai, A., Tran, H., Roberts, M., Clark, N., Gibson, A M., Vidmar, S., ... Robertson, C. F. (2014). Outcomes of childhood asthma to the age of 50 years. Journal of Allergy and Clinical Immunology, 133, 1572-1578.

The Childhood Asthma Management Program Research Group. (2000). Long term effects of budesonide or nedocromil in children with asthma. New England Journal of Medicine, 343, 1054-1063.

Thomsen, S. F., Kyvik, K. O., \& Backer, V. (2008). Etiological relationships in atopy: A review of twin studies. Twin Research and Human Genetics, 11, 112-120.

Thomsen, S. F., van der Sluis, S., Kyvik, K. O., Skytthe, A., \& Backer, A. (2010). Estimates of asthma heritability in a large twin sample. Clinical and Experimental Allergy, 40, 1054-1064.

Umlawska, W., Gaszczyk, G., \& Sands, D. (2013). Physical development in children and adolescents with bronchial asthma. Respiratry Physiology and Neurobiology, 187, 108113.

van den Berg, S. M., Setiawan, A., Bartels, M., Polderman, T. J., van der Vaart, A. W., \& Boomsma, D. I. (2006). Individual differences in puberty onset in girls: Bayesian estimation of heritabilities and genetic correlations. Behavior Genetics, 36, 261-270.

Wang, Y., Dinse, G. E., \& Rogan, W. J. (2012). Birth weight, early weight gain and pubertal maturation: A longitudinal study. Pediatric Obesity, 7, 101-109.

WHO Expert Committee on Physical Status. (1995). Physical status: The use and interpretation of anthropometry. Retrieved from http://whqlibdoc.who.int/trs/ WHO'TRS 854.pdf.

Yoshitake, N., Okusa, M., Sasaki, S., Kunitsugu, I., \& Hobara, T. (2012). Validity of self-reported body mass index of Japanese children and adolescents. Pediatrics International, $54,397-401$. 